06.5;05.3

\title{
Индий-индуцированная кристаллизация тонких пленок аморфного субоксида кремния
}

\author{
(C) А.О. Замчий ${ }^{1,2}$, Е.А. Баранов ${ }^{1}$, И.Е. Меркулова ${ }^{1,2}$, Н.А. Лунев ${ }^{1}$, В.А. Володин ${ }^{2}$, Е.А. Максимовский ${ }^{3}$ \\ ${ }^{1}$ Институт теплофизики им. С.С. Кутателадзе СО РАН, Новосибирск, Россия \\ ${ }^{2}$ Новосибирский государственный университет, Новосибирск, Россия \\ ${ }^{3}$ Институт неорганической химии им. А.В. Николаева СО РАН, Новосибирск, Россия \\ E-mail: zamchiy@gmail.com
}

Поступило в Редакцию 23 января 2020 г.

В окончательной редакции 20 марта 2020г.

Принято к публикации 20 марта 2020г.

Предложен новый метод получения поликристаллического кремния путем индий-индуцированной кристаллизации тонких пленок аморфного субоксида кремния со стехиометрическим коэффициентом $0.5\left(a-\mathrm{SiO}_{0.5}\right)$. Показано, что использование индия в процессе отжига $a-\mathrm{SiO}_{0.5}$ позволяет снизить температуру кристаллизации до $600^{\circ} \mathrm{C}$, что существенно ниже температуры твердотельной кристаллизации такого материала $\left(850^{\circ} \mathrm{C}\right)$. В результате процесса индий-индуцированной кристаллизации $a-\mathrm{SiO}_{0.5}$, протекающего в высоком вакууме, происходит формирование свободностоящих частиц кристаллического кремния микронного размера.

Ключевые слова: тонкие пленки, субоксид кремния, индий-индуцированная кристаллизация, поликристаллический кремний.

DOI: 10.21883/PJTF.2020.12.49520.18220

На данный момент тонкие пленки поликристаллического кремния (poly-Si) на дешевых подложках из несобственного материала, например стекла, находят широкое применение в производстве полупроводниковых приборов большой площади, таких как солнечные элементы и тонкопленочные транзисторы $[1,2]$. Наиболее распространенными способами получения тонких пленок poly-Si на нетугоплавких подложках из несобственного материала являются методы твердофазной кристаллизации (solid phase crystallization, SPC) [3], жидкофазной кристаллизации (liquid phase crystallization, LPC) [4] и металлоиндуцированной кристаллизации (metal-induced crystallization, MIC) [1] аморфного кремния ( $a-\mathrm{Si})$. Meтод МIC основан на использовании различных металлов (алюминия, золота, никеля) [5], индуцирующих кристаллизацию $a$-Si в процессе изотермического отжига. В процессе отжига металл выступает в качестве катализатора кристаллизации, что позволяет снизить температуру и время процесса.

В настоящей работе впервые показана возможность получения poly-Si путем индий-индуцированной кристаллизации (indium-induced crystallization, InIC) аморфного субоксида кремния $\left(a-\mathrm{SiO}_{x}, 0<x<2\right)$ [6]. Индий относится к группе металлов, не образующих с кремнием силицидов, совместим с кремниевой технологией, широко используется в электронике и фотовольтаике, а также обладает низкой температурой плавления $\left(157^{\circ} \mathrm{C}\right)$. Ранее авторами были получены пленки poly-Si в процесce MIC $a-\mathrm{SiO}_{x}$ с использованием алюминия [7,8].

Тонкие пленки $a-\mathrm{SiO}_{x}$ толщиной $400 \mathrm{~nm}$ были получены из газовой смеси $\mathrm{SiH}_{4}-\mathrm{O}_{2}$ методом плазмохимического осаждения с использованием широкоапертурного источника с индуктивным высокочастотным возбуждением (13.56 MHz). Мощность высокочастотного излучения составляла $50 \mathrm{~W}$, температура подложки $-150^{\circ} \mathrm{C}$. В качестве подложек использовались боросиликатное стекло и кварц. Методом энергодисперсионной рентгеновской спектроскопии был определен стехиометрический коэффициент $x=0.5$. Затем на $a-\mathrm{SiO}_{0.5}$ были нанесены пленки In толщиной около $420 \mathrm{~nm}$ методом термовакуумного осаждения. Далее полученные образцы были подвергнуты высоковакуумному печному отжигу (остаточный вакуум $\left.\sim 10^{-4} \mathrm{~Pa}\right)$ при температурах $500-850^{\circ} \mathrm{C}$ в течение $5 \mathrm{~h}$. Структура отожженных образцов была исследована методом комбинационного рассеяния света (КРС) с использованием прибора T64000 Horiba JobinYvon в обратной геометрии рассеяния на длине волны $514.5 \mathrm{~nm}$. Диаметр светового пятна зондирующего излучения составлял $5 \mu \mathrm{m}$. Оптический микроскоп (OM), интегрированный с КРС-спектрометром, был использован для исследования морфологии полученного материала. Более детальное изучение морфологии образцов осуществлялось методом сканирующей электронной микроскопии (СЭМ) на приборе JEOL JSM-6700F.

Согласно данным, полученным при помощи СЭМ, исходная пленка $\mathrm{In}$, напыленная на слои $a-\mathrm{SiO}_{0.5}$, несплошная, имеет островковую структуру и состоит из отдельных частиц неправильной формы двух размерных фракций. Средний размер крупной фракции составляет около $1 \mu \mathrm{m}$, мелкой - около $100 \mathrm{~nm}$. Изображения образцов, отожженных при температурах 550,600 и $850^{\circ} \mathrm{C}$, полученные при помощи ОМ, показаны на рис. $1, a-c$. Отжиг образца при температуре $550^{\circ} \mathrm{C}$ приводит к температурному деветтингу пленки In, а также к уве- 

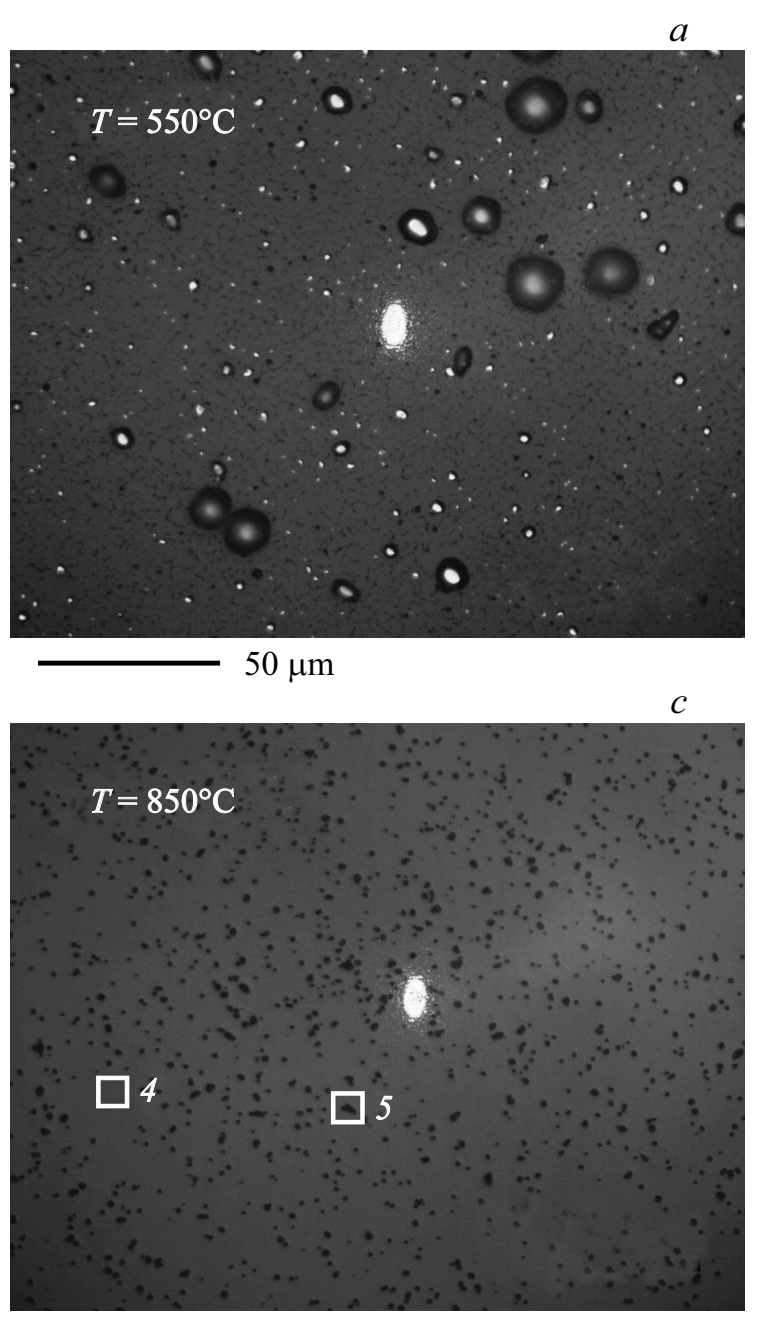

$50 \mu \mathrm{m}$

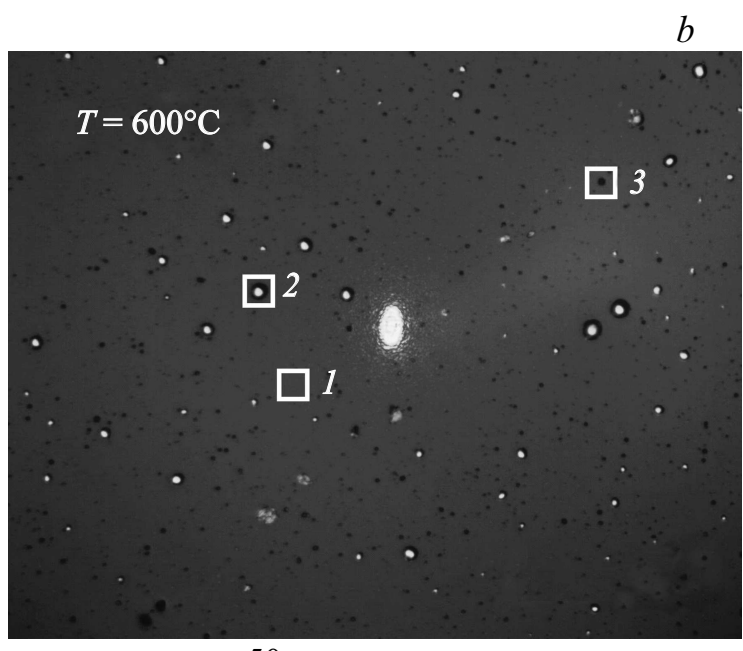

$50 \mu \mathrm{m}$
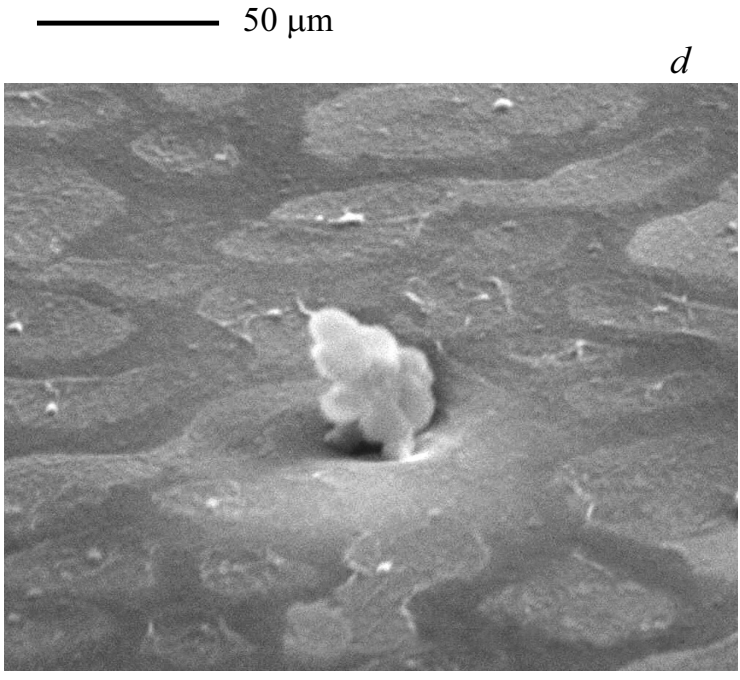

$5 \mu \mathrm{m}$

Рис. 1. Изображения поверхности образцов, отожженных при температурах $550(a), 600(b)$ и $850^{\circ} \mathrm{C}(c)$, полученные при помощи OM. $d$ - изображение области 3 , отмеченной на части $b$, полученное при помощи СЭМ.

личению среднего размера частиц металла по сравнению с исходным в результате процесса коалесценции (рис. $1, a)$. Отжиг при $600^{\circ} \mathrm{C}$ приводит к существенному уменьшению как среднего размера, так и поверхностной концентрации частиц In (рис. $1, b)$ по сравнению с наблюдаемыми при более низкой температуре отжига, что вызвано испарением металла с поверхности образца [9]. Также на рис. $1, b$ можно отметить три характерных морфологии материала, формирующегося в результате отжига при $600^{\circ} \mathrm{C}$. Во-первых, не покрытая частицами In пленка субоксида кремния (область 1). Во-вторых, частицы In на поверхности пленки субоксида кремния (область 2). Области с описанной морфологией характерны также для материала, отожженного при $550^{\circ} \mathrm{C}$ (рис. 1,a). В-третьих, в процессе отжига при $600^{\circ} \mathrm{C}$ происходит формирование темных областей микронного размера (область 3 на рис. 1,b), которые, вероятнее всего, образуются на месте испарившегося In. Указанная морфология отсутствует в образцах, отожженных при более низких температурах. Увеличение температуры процесса до $850^{\circ} \mathrm{C}$ приводит к полному испарению In с поверхности образца (рис. 1,c). Для данных условий отжига в образце различима морфология двух видов: пленка субоксида кремния (область 4), а также темные области (область 5), концентрация которых существенно выше, чем в образцах с более низкими температурами процесса отжига. Более детальное исследование морфологии области 3, выполненное при помощи СЭМ (рис. $1, d)$, показало формирование структур микронного размера, возвышающихся над поверхностью образца и находящихся при этом во впадинах.

Структурные свойства областей 1-5 были исследованы методом спектроскопии КРС (рис. 2). Анализ полученных спектров показал, что область 1 представляет собой аморфный материал, содержащий значительное количество кремниевых связей (спектр 1 на рис. 2), о чем свидетельствует наличие оптической моды поперечных колебаний (ТО-мода) с центром на 


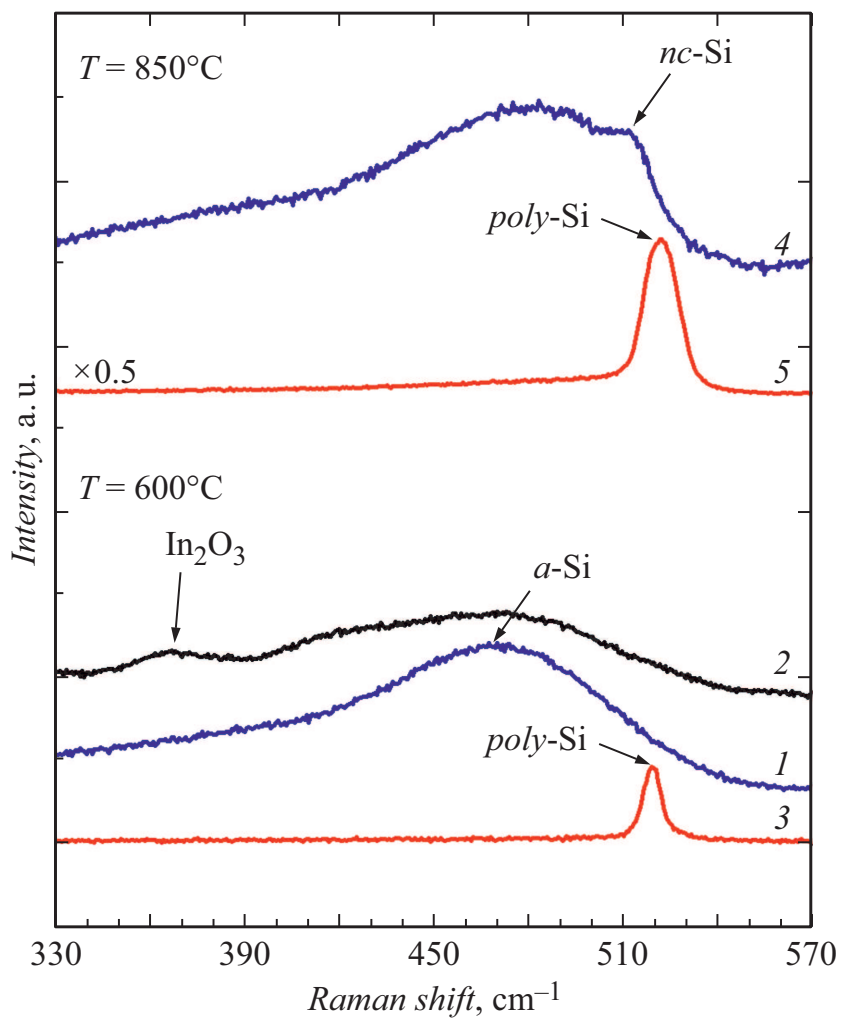

Pис. 2. Спектры КРС образцов, отожженных при температурах 600 и $850^{\circ} \mathrm{C}$, полученные для областей, отмеченных светлыми квадратами на рис. $1, b, c$. Номера спектров соответствуют номерам областей исследования. Интенсивность спектра 5 уменьшена в 2 раза по сравнению с интенсивностями других спектров.

$\sim 480 \mathrm{~cm}^{-1}$ [6]. Область 2 соответствует кристаллическому $\mathrm{In}_{2} \mathrm{O}_{3}$ (ТО-мода с центром на $\sim 365 \mathrm{~cm}^{-1}$ ) [10]. При этом пятно зондирующего пучка частично попадало на область 1 (спектр 2). Симметричный узкий пик с центром на $\sim 520 \mathrm{~cm}^{-1}$ на спектрах 3 , 5 свидетельствует о формировании poly-Si в соответствующих областях на поверхности образцов [7]. При этом сигнал, соответствующий аморфному кремниевому материалу, в спектрах отсутствует. Следует отметить, что с ростом температуры интенсивность сигнала КРС возрастает, что указывает на увеличение количества формирующегося материала poly-Si. Увеличение температуры отжига до $850^{\circ} \mathrm{C}$ приводит к формированию нанокристаллического кремния $(n c-\mathrm{Si})$ в области 4 в процессе SPC $[11,12]$, о чем свидетельствует появление в спектре 4 пика с центром на $\sim 513 \mathrm{~cm}^{-1}$. Полученная согласно положению пика величина среднего размера кристаллита составляет $\sim 4 \mathrm{~nm}[12]$.

При температурах выше точки эвтектики системы кремний-индий $\left(157^{\circ} \mathrm{C}\right)$ происходит формирование эвтектического сплава путем взаимной диффузии атомов через линию контакта In и $a-\mathrm{SiO}_{0.5}$. В результате обогащения такого сплава кремнием происходит пересыщение, которое приводит к формированию структур кристаллического кремния [13]. По-видимому, поток атомов кремния в частицу In выше, что в совокупности с испарением In в условиях высоковакуумного отжига приводит к формированию свободностоящих частиц кристаллического кремния, располагающихся во впадинах. Следует отметить, что получение и изучение свойств подобных кремниевых структур представляется весьма привлекательной задачей. В частности, такие структуры легко могут быть нагреты вплоть до температуры плавления при помощи зондирующего излучения стандартного КРС-спектрометра [14].

В работе предложен новый метод получения poly-Si методом индий-индуцированной кристаллизации тонких пленок $a-\mathrm{SiO}_{0.5}$. Показано, что процесс $\mathrm{InIC} a-\mathrm{SiO}_{0.5}$ протекает при более низких температурах $\left(600^{\circ} \mathrm{C}\right)$, чем процесс твердотельной кристаллизации аморфного субоксида кремния, нижней температурной границей которого является значение $850^{\circ} \mathrm{C}$, что позволяет использовать низкотемпературные подложки. В результате процесса InIC $a-\mathrm{SiO}_{0.5}$, протекающего в высоком вакууме, происходит формирование свободностоящих частиц кристаллического кремния микронного размера.

\section{Благодарности}

Авторы выражают благодарность ЦКП „ВТАН“ НГУ за предоставление оборудования для регистрации спектров КРС.

\section{Финансирование работы}

Исследование выполнено при финансовой поддержке гранта Президента РФ (МК-638.2019.8) (напыление In, высоковакуумный печной отжиг образцов) и в рамках государственного задания ИТ СО РАН (синтез и характеризация пленок $\left.a-\mathrm{SiO}_{x}\right)$.

\section{Конфликт интересов}

Авторы заявляют, что у них нет конфликта интересов.

\section{Список литературы}

[1] Maity G., Singhal R., Dubey S., Ojha S., Kulriya P.K., Dhar S., Som T., Kanjilal D., Patel S.P. // J. Non-Cryst. Solids. 2019. V. 523. P. 119628. doi.org/10.1016/j.jnoncrysol.2019.119628

[2] Nguyen T.T., Hiraiwa M., Koganezawa T., Yasuno S., Kuroki S.-I. // Jpn. J. Appl. Phys. 2018. V. 57. P. 031302. doi.org/10.7567/JJAP.57.031302

[3] Kumar A., Widenborg P.I., Dalapati G.K., Ke C., Subramanian G.S., Aberle A. // Cryst. Growth Design. 2015. V. 15. P. 1067-1072. doi.org/10.1021/cg5011659

[4] Haschke J., Amkreutz D., Rech B. // Jpn. J. Appl. Phys. 2016. V. 55. P. 04EA04. doi.org/10.7567/JJAP.55.04EA04

[5] Wang Z., Jeurgens L.P.H., Mittemeijer E.J. Metal-induced crystallization: fundamentals and applications. 1st ed. Boca Raton: CRC Press Taylor \& Francis Group, 2015. 308 p. doi.org/10.1201/b18032 
[6] Баранов Е.А., Замчий А.О., Хмель С.Я. // Письма в ЖТФ. 2015. Т. 41. В. 20. С. 89-95. [Пер. версия: 10.1134/S1063785015100181].

[7] Zamchiy A.O., Baranov E.A., Khmel S.Ya., Volodin V.A., Vdovin V.I., Gutakovskii A.K. // Appl. Phys. A. 2018. V. 124. P. 646. doi.org/10.1007/s00339-018-2070-y

[8] Zamchiy A.O., Baranov E.A., Maximovskiy E.A., Volodin V.A., Vdovin V.I., Gutakovskii A.K., Korolkov I.V. // Mater. Lett. 2020. V. 261. P. 127086. doi/10.1016/j.matlet.2019.127086

[9] Kang D.-H., Park J.-H. // Mater. Res. Bull. 2014. V. 60. P. 814-818. doi.org/10.1016/j.materresbull.2014.09.037

[10] Berengue O.M., Rodrigues A.D., Dalmaschio C.J., Lanfredi A.J.C., Leite E.R., Chiquito A.J. // J. Phys. D: Appl. Phys. 2010. V. 43. P. 045401. DOI: 10.1088/0022-3727/43/4/045401

[11] Van Sebille M., Fusi A., Xie L., Ali H., van Swaaij R.A.C.M.M., Leifer K., Zeman M. // Nanotechnology. 2016. V. 27. P. 365601. DOI: $10.1088 / 0957-4484 / 27 / 36 / 365601$

[12] Zamchiy A.O., Baranov E.A., Merkulova I.E., Volodin V.A., Sharafutdinov M.R., Khmel S.Y. // Vacuum. 2018. V. 152. P. 319-326. doi.org/10.1016/j.vacuum.2018.03.055

[13] Neimash V.B., Goushcha A.O., Shepeliavyi P.E., Yukhymchuk V.O., Dan'ko V.A., Melnyk V.V., Kuzmich A.G. // Ukr. J. Phys. 2014. V. 59. P. 1168-1176.

DOI: $10.15407 /$ ujpe59.12.1168

[14] Han L., Zeman M., Smets A.H.M. // Nanoscale. 2015. V. 7. P. $8389-8397$. DOI: $10.1039 / \mathrm{c} 5 \mathrm{nr} 00468 \mathrm{c}$ 